\section{Repolitizar los territorios. Reflexiones sobre los conceptos de territorio y poder en la extensión universitaria}

Fabio Erreguerena

Universidad Nacional de Cuyo, Argentina.

ferreguer@uncu.edu.ar

(iD) orcid.org/0000-0003-0779-0933
Sujetos y relaciones en extensión universitaria / Perspectivas

\section{다(1)(2)}

RECEPCIÓN: 26/06/20

ACEPTACIÓN FINAL: 07/09/20

\section{Resumen}

En este artículo nos proponemos hacer un breve repaso por los distintos significados $e$ implicancias de la categoría de "territorio", categoría de uso cotidiano en el campo de la extensión universitaria y que, desde hace ya más de cuatro décadas y con una participación relevante de autores latinoamericanos, ha tenido importantes resignificaciones. Teniendo en cuenta que para los autores que desarrollaremos, $y$ para nuestra propia perspectiva, el territorio constituye un espacio social y culturalmente producido que expresa relaciones de poder, indagaremos distintas nociones sobre el poder implicadas, dado que las mismas arrojarán diferentes concepciones acerca del territorio. Por otra parte, fundamentaremos el rol clave que juega la dimensión territorial en la constitución e identidad de los actores, organizaciones y movimientos sociales en Latinoamérica, una característica diferencial de la acción colectiva en nuestro continente. Finalmente, intentaremos reflexionar acerca de la necesidad de no descuidar las dinámicas políticas y de conflicto presentes, explícitas o implícitamente, en las prácticas extensionistas tanto dentro del territorio universitario como en el extrauniversitario.
Repolitizing the territories. Reflections on the concepts of territory and power in university extension

\section{Abstract}

In this article we make a brief review of the different meanings and implications of the category of "territory", a category of daily use in the field of university extension. For more than four decades, the concept of territory has been delved by relevant Latin American thinkers and it has had important local resignifications. In this direction, territory is understood as a space that is socially and culturally produced, related with power relations. Accordingly, the notion of power will be addressed in order to examine its relation with the concept of territory to see their effects in the practice of university extension. we will argue that territory plays a main role in the constitution and identity of the actors, organizations and social movements in Latin America, a singular feature of collective action in our continent. Finally, we will try to reflect the impact of the political dynamics and conflict present, explicitly or implicitly, in extension practices, both within the university and outside the university.

Keywords: territory; university extension; power.
Repolitizar os territórios. Reflexões sobre os conceitos de território e poder na extensão universitária

\section{Resumo}

Neste artigo nos propomos fazer uma breve revisão dos diferentes significados e implicações da categoria de "território", uma categoria de uso cotidiano no campo da extensão universitária e que, há mais de quatro décadas e com uma participação relevante de autores latino-americanos, teve importantes ressignificações. Tendo em vista que, para os autores que iremos apresentar, e para a nossa perspectiva, o território constitui um espaço produzido social e culturalmente e que expressa relações de poder, pesquisaremos diferentes noções de poder envolvidas, já que revelarão diferentes concepções sobre o território. Por outro lado, estabeleceremos o papel fundamental que a dimensão territorial desempenha na constituição e identidade dos atores, organizações e movimentos sociais na América Latina, um diferencial da ação coletiva em nosso continente. Por fim, buscaremos refletir sobre a necessidade de não negligenciar a dinâmica política e de conflito presente, explícita ou implicitamente, nas práticas de extensão, tanto dentro como fora da universidade.

Palavras-chave: território; extensão universitária; poder.

Palabras clave: territorio; extensión universitaria; poder.

Para citación de este artículo: Erreguerena, F. (2020). Repolitizar los territorios. Reflexiones sobre los conceptos de territorio y poder en la extensión universitaria. +E: Revista de Extensión Universitaria, 10(13), e0012. doi: 10.14409/extension.2020.13.Jul-Dic.e0012 


\section{Introducción ${ }^{1}$}

Este trabajo se inscribe en las reflexiones y prácticas de una tradición, la extensionista, cuya polisemia (multiplicidad de significados), presente ya en el propio concepto de extensión universitaria, se ha hecho más evidente a medida que avanza la discusión e investigación sobre sus herramientas conceptuales y metodológicas. Por otra parte, existe un conjunto de categorías cuyos significados y alcances, más allá de su uso analítico, académico o normativo, es reformulado de manera constante por su uso cotidiano. Periódicamente utilizada por los actores, organizaciones y movimientos sociales, especialmente latinoamericanos, la categoría de "territorio" tiene una permanente y fructífera resignificación.

En el caso universitario, y dentro del campo de la extensión universitaria en particular, es muy frecuente referirnos al "territorio" como aquel espacio, otro, no universitario, donde se despliegan las acciones que cristalizan el compromiso social de la universidad. Es en el territorio donde se alojan los actores extrauniversitarios, ya sean estos personas individuales, organizaciones y/o movimientos sociales. Como sostiene Mariana Arzeno (2018), dentro del campo de la extensión universitaria el territorio aparece como el terreno donde la teoría se vuelve práctica, donde se produce el intercambio, el lugar donde la universidad se conecta de manera concreta con la realidad social para interactuar y en ese proceso generar nuevas formas de aprendizaje.

Al igual que con la noción de "comunidad" o "barrio", en general, hay en el uso del concepto de territorio una homogeneización y despolitización de las relaciones sociales allí cobijadas que impide dar cuenta de las múltiples relaciones y conflictos que conviven y en las cuales, inevitablemente, nos involucramos en nuestro trabajo extensionista. Como ejercicio para pensar nuestro uso del concepto de territorio conviene también señalar que ese "otro" es nombrado como un territorio, pero la propia universidad rara vez es concebida como territorio. Entonces es necesario preguntarnos: ¿acaso la universidad no constituye, justamente, un territorio? ¿Existe ese espacio denominado comúnmente "la universidad" que, muchas veces y al igual que con el territorio extrauniversitario, la pensamos y visualizamos exento de conflictos? ¿Qué implicancias tiene este álter ego "universidad/territorio" en los relatos y las prácticas que se desarrollan en el ámbito de la extensión universitaria? ¿Acaso la universidad como territorio no es, a su vez, objeto de múltiples territorializaciones por parte de sus actores (los territorios que generan sus diversos claustros, las agrupaciones políticas, los alineamientos disciplinares e institucionales, redes de género, ámbitos gremiales, etc.)? Este asunto resulta central para intentar despejar los muros que tradicionalmente separan a la universidad de las organizaciones y movimientos sociales y que persisten más allá de la buena voluntad de los/las extensionistas.

En este trabajo sostenemos que las actoras y los actores universitarios y extrauniversitarios se encuentran siempre inscriptos en territorios (universitario y extrauniversitario) que han sido social y culturalmente producidos y expresan las relaciones de poder allí contenidas, en las que todos y todas estamos atravesados y jugamos un papel para su consolidación, debilitamiento o refuerzo. Por otra parte, cabe mencionar que la reflexión propuesta tiene como objetivo favorecer la discusión y desarrollo de la corriente de Extensión Crítica Latinoameri- 
cana y Caribeña ( $E C L$ y $C$ ), espacio en el que nos inscribimos y pretendemos aportar a su expansión. Recordemos que dicha corriente surge en los años 90, inicialmente como respuesta a los formatos hegemónicos de relación con el medio (modelo de transferencia tecnológica/ venta de servicios) que imponía el clima de época. Retoma el legado de la Reforma del '18 y la tradición del pensamiento crítico latinoamericano y, como sostienen Humberto Tommasino y Nicolás Rodríguez (2011), implica un proceso:

- transformador, donde no hay roles estereotipados de educador y educando (todos pueden aprender y enseñar);

- que contribuye a la producción de conocimiento nuevo y que vincula críticamente el saber académico con el saber popular;

- que promueve diversas formas organizativas (asociativas y grupales) que aportan a superar problemáticas sociales de relevancia;

- que favorece la consolidación de las prácticas educativas integrales y la articulación de la investigación, la enseñanza, el aprendizaje y la extensión en la intimidad del acto educativo;

- con abordaje interdisciplinario, con la presencia y el trabajo en conjunto entre actores sociales y universitarios en todas y cada una de las etapas: construcción de la demanda, planificación, ejecución y evaluación.

Todo ello en el marco de una lectura crítica al orden social vigente; un propósito claro de contribuir al fortalecimiento de los sectores dominados como sujetos históricos protagonistas del cambio social y el impulso a procesos sociales y políticos anticapitalistas, antipatriarcales y decoloniales.

En las páginas siguientes nos proponemos hacer un breve repaso por los distintos significados del concepto de territorio y su relación, en gran medida original, con los actores, organizaciones y movimientos sociales en Latinoamérica. Para ello hemos organizado este escrito en tres partes. En la primera abordaremos las tradiciones y derivas del concepto de territorio como insumo para, ya en la segunda parte, sumergirnos en diferentes nociones sobre el poder. En la tercera parte fundamentaremos la centralidad de la dimensión y perspectiva territorial en la constitución y dinámica de los movimientos sociales en Latinoamérica. Finalmente, en las conclusiones, esperamos retomar los distintos temas y argumentar la necesidad de repolitizar los territorios y la extensión.

\section{¿De qué hablamos cuando hablamos de territorio?}

El concepto de territorio adquiere especial relevancia en el siglo XIX, en el marco de la consolidación de los Estados nacionales en Europa. La necesidad de establecer límites geográficos en un contexto donde mayores territorios determinaban mayor riqueza y poder marcará este primer significado del concepto de territorio, ligado fundamentalmente al espacio geográfico natural y al poder centralizado en el Estado. Sin desconocer los debates que antecedieron, pero que escapan a los objetivos del presente artículo, será entre los años de 1960 y 1980 cuando, en el marco de una profunda revisión de sus tradiciones fundacionales, la geografía y otras disciplinas revisen los significados e implicancias de las nociones de territorio. La denominada "geografía crítica", en un fructífero cruce disciplinar con la sociolo- 
gía, la antropología y la historia, incorporará al poder y el conflicto social en los análisis del territorio. Según Rogerio Haesbaert (2013), distintos autores influenciaron este giro teórico de la geografía, entre quienes se destacan Michel Foucault, Claude Raffestain y Robert Sack. En abierta crítica a la noción de territorio definido en función del poder centralizado en el Estado, Raffestain (1993) propondrá la diferenciación entre "espacio" y "territorio", siendo espacio un concepto previo a territorio, y siendo el territorio una producción, a partir del espacio, atravesada por relaciones sociales y de poder. En tanto, para Sack (1986), el territorio es todo espacio que tiene el acceso controlado, por lo cual, desde el momento en que se controla espacial y materialmente el acceso de algún flujo (mercancías, personas, capital), se está transformando el espacio en un territorio.

Bárbara Altschuler (2013) analiza la definición de territorio propuesta por Sack y comenta que la misma se alejó de una noción de territorialidad derivada del instinto y el comportamiento animal ya que, desde la perspectiva de Sack, un área se convierte en territorio solamente cuando sus límites son utilizados para influenciar el comportamiento de las personas a través del control de acceso de esos límites. De esta forma, los territorios poseerían diferentes niveles de permeabilidad y accesibilidad para las personas, objetos o flujos de diverso tipo. Para la autora, los aspectos más significativos del aporte de Sack son tres. En primer lugar, un enfoque histórico de la territorialidad, ya que, para este autor, esta no ha sido igual a lo largo del tiempo sino que se ha ido modificando, lo cual implica que la territorialidad es construida socialmente. En segundo lugar, la flexibilidad y amplitud de su concepto de territorio, puesto que por este puede entenderse desde un país o el territorio de una comunidad indígena hasta una cárcel o una parte de nuestra casa. Por último, resulta fundamental la centralidad puesta desde su perspectiva en el control y las relaciones de poder, pero dejando asimismo lugar para la interpretación del territorio como el contexto a través del cual experimentamos el mundo y le damos significado, es decir, desde una perspectiva no solo político- jurídica sino también simbólica y cultural. Por su parte, Mabel Manzanal (2014) destaca que existe consenso, en las definiciones de Raffestein y Sack, en asociar al territorio con la producción social del espacio. Es a través de la práctica social de los actores que el territorio se construye diferencialmente. En función de ello, cuando buscamos explicar las causas que llevan a la producción de diferentes espacialidades, entendiendo el espacio como una producción social, necesitamos focalizar en las relaciones de poder constituyentes.

Los debates acerca del significado de territorio han sido muy fructíferos en América Latina, a veces dialogando con las conceptualizaciones arriba expuestas, a veces no. Marcelo Lopes de Souza (2001) propone una definición que puede resultar especialmente pertinente para el campo extensionista. Para este autor, el territorio "es el espacio definido y delimitado por y a partir de relaciones de poder" (p. 78). Para Lopes de Souza, el territorio puede estar relacionado a formas jurídico-políticas (un Estado-nación), culturales (una organización barrial) y/o económicas (una empresa). En definitiva, el territorio puede asumir las más diversas escalas, formas y manifestaciones, desde pequeños territorios (una plaza, un barrio) hasta un territorio red de una gran multinacional que posee sus ramificaciones en varios países.

Haesbaert (2011) procura definir la relación entre el concepto de espacio y el concepto de territorio. Concibe al territorio como el resultado de un proceso de territorialización sobre el espacio, proceso que implica un dominio (aspecto económico-político) y una apropiación (aspecto simbólico-cultural) de los espacios por los grupos humanos. Plantea la necesidad 
de una visión de territorio a partir de la concepción de espacio como un híbrido, híbrido entre sociedad y naturaleza, entre política, economía y cultura, y entre materialidad e idealidad. El autor, teniendo como plano de fondo esta noción híbrida de espacio geográfico, plantea que el territorio puede ser concebido a partir de la imbricación de múltiples relaciones de poder, del poder más material de las relaciones económico-políticas al poder más simbólico de las relaciones de orden más estrictamente cultural.

Otros autores también harán hincapié en la dimensión de apropiación que supone todo proceso de territorialización de los espacios. En este sentido, Bernardo Mançano Fernandes (2017) afirma que no basta solamente con hablar de territorios, sino que es preciso definir cuál territorio, puesto que las clases y las relaciones sociales no son ajenas a los mismos sino sus productoras y su producto. Para Mançano Fernandes el territorio es "el espacio apropiado por una determinada relación social que lo produce y lo mantiene a partir de una forma de poder" $(2005$, p. 3). Si bien el territorio es un espacio socialmente ordenado, no deja de ser un espacio de conflictividad ya que presupone una disputa por la definición de ese orden y por el control que los grupos sociales tienen sobre él. Recupera el carácter multidimensional de la noción de territorio y destaca que la conflictividad constituye un rasgo inherente a los procesos de territorialización.

El análisis de Mançano Fernandes, fuertemente anclado en las experiencias de los movimientos socioterritoriales brasileños, en especial el Movimiento de Trabajadores Rurales Sin Tierra (MST), nos introduce a un aspecto relevante y en muchos aspectos decisivo para el significado que le daremos al concepto de territorio: analizar qué entendemos por poder. Ello en el sentido de que, de acuerdo con el concepto de poder adoptado, cambiará el significado de territorio.

\section{Pensar el poder para complejizar el territorio}

El control del espacio posibilita las condiciones para dominar la dinámica de poder allí desarrollada, una dinámica profunda y esencialmente social. Por ello, según la noción de poder que, explícita o implícitamente, adoptemos, será la noción implicada de territorio. Haesbaert (2013) explica que si, por ejemplo, adoptamos la versión más tradicional de poder, referida al poder del Estado y/o de la clase hegemónica, el territorio será pensado como un macroterritorio básicamente vinculado a las grandes estructuras político-económicas dominantes. Pero si se piensa que el poder también se manifiesta como movimiento de resistencia que está involucrado en todo tipo de relación social, tendremos microterritorios y habrá muchas otras formas de reconstruir el poder y el territorio a partir de esta concepción que, sobre todo para Latinoamérica, es muy interesante en función del papel de resistencia y territorialización de los movimientos sociales.

En este sentido, el concepto relacional del poder, cuyo principal exponente es Michel Foucault, es muy fructífero para analizar el territorio en Latinoamérica porque, entre otras cosas, reconoce los saberes subalternos, algo clave para la extensión universitaria. Y, sobre todo, porque postula que donde hay poder hay resistencia y esa posibilidad de resistencia es central en la perspectiva territorial de los movimientos sociales latinoamericanos. Aunque el mismo Foucault aclara que no constituyó un propósito relevante de sus investigaciones elaborar una teoría acerca del poder, sus hipótesis y las densas descripciones acerca del fun- 
cionamiento de sus distintos dispositivos nos permiten extraer un conjunto de conclusiones en cuanto a su funcionamiento, prácticas y efectos. Un primer acercamiento al pensamiento de Foucault (1990) es considerar que, para este, las relaciones de poder no están en posición de exterioridad respecto de otros tipos de relaciones (sociales, económicas, sexuales, territoriales) sino que son inherentes (inmanentes, dirá) y constitutivas de toda relación social. El poder no es una propiedad, un bien, sino una relación, una estrategia y, en función de ello, en toda relación social hay relaciones de poder.

"El poder no es algo que se adquiera, arranque o comparta, algo que se conserve o deje escapar; el poder se ejerce a partir de innumerables puntos, y en el juego de relaciones móviles y no igualitarias". (Foucault, 1990, p. 114)

Estos escritos de Foucault, en el marco del contexto histórico de su tiempo, con las revueltas estudiantiles de 1968 como hito, fueron parte del surgimiento de nuevas miradas políticas y teóricas que observaban fenómenos en general excluidos de los relatos teóricos dominantes (género, orientación sexual, etnia, música, paz, ecología) y que colaboraron para generar nuevas concepciones acerca de la complejidad social. Uno de los principales planteos del francés, que modificó las tradiciones teóricas existentes hasta ese momento, fue su argumento acerca de que el Estado y los distintos grupos sociales hacen uso del poder pero no existe un lugar donde este se aloje y concentre (el Estado, las clases dominantes, por ejemplo) y a partir de allí se derrame, sino que el poder se encuentra incrustado en toda relación social. Así, Foucault traslada el análisis del poder desde superestructuras como el Estado o instrumentos como la ley, hacia el estudio exhaustivo de sus mecanismos cotidianos más pequeños. A diferencia de los enfoques tradicionales acerca del poder como el enfoque jurídico-político (centrado en la ley y el Estado), el del marxismo tradicional (el poder como propiedad de la clase dominante) y la hipótesis represiva (el poder en términos de represividad negativa), Foucault propondrá una noción productiva, creadora del poder. Para Foucault el poder no actúa, al menos no solamente, mediante la represión (prohibiendo, negando, censurando, excluyendo) sino a través de la "normalización". En la óptica del autor, hay mayor poder cuando se normaliza una conducta que cuando se la prohíbe. En este sentido, y según Gilles Deleuze (1987):

"Foucault muestra que la ley no es ni un estado de paz ni el resultado de una guerra ganada: es la guerra, la estrategia de esa guerra en acto, de la misma manera que el poder no es una propiedad adquirida de la clase dominante, sino un ejercicio actual de la estrategia". (p. 56)

Lo que busca el poder es que los individuos se autorregulen y autocontrolen sustentados en establecer como "normal" determinadas conductas e ideas (acerca de la vida, sexo, moral, autoridad, etc.) en lugar de otras posibles. El poder es creador, produce activamente sujetos, discursos, saberes, verdades, instituciones y prácticas que atraviesan y son inmanentes a las relaciones sociales.

"Las relaciones de poder no se hallan en posición de superestructura, con un simple papel de prohibición o reconducción; desempeñan, allí en donde actúan, un papel directamente productor". (Foucault, 1990, p. 114) 
Para Foucault, distintos dispositivos de poder serán preponderantes en determinados momentos históricos, e identifica al Poder Soberano (control del territorio, límites); Poder Disciplinario (control de los individuos-cuerpos) y la biopolítica (seguridad, gobierno de la población). No obstante, como sostiene Edgardo Castro (2015), no hay una linealidad histórica entre dichos dispositivos, como si hubiese una época arcaica, la de la soberanía; otra moderna, la de las disciplinas; y otra contemporánea, la de la seguridad y la biopolítica. Históricamente, no hay una sucesión de estos diferentes dispositivos sino una simultaneidad. Lo que cambia de una época a otra es el modo en que estas diferentes formas de ejercicio del poder se relacionan entre sí y, en el marco de este juego, cuál de estos dispositivos cumple la función dominante.

El análisis de Foucault y la centralidad de la noción de poder en las significaciones del territorio nos introducen a un aspecto relevante, y en muchos aspectos original, de gran parte de los actores, organizaciones y movimientos sociales en Latinoamérica: su dimensión y perspectiva territorial.

\section{La territorialidad como dimensión constituyente de los actores, organizaciones y movimientos sociales en Latinoamérica}

Diversos autores de distintos países, tradiciones teóricas y disciplinas, confluyen en señalar la relevancia del territorio en los procesos de identidad de los actores, organizaciones y movimientos sociales latinoamericanos. Maristella Svampa (2017) sostiene que hay un consenso implícito entre diferentes analistas latinoamericanos (como Mançano Fernandes, Santos, Porto Gonçalves, Giarraca, Palau, Zibecchi) acerca de que una de las dimensiones constituyentes de los movimientos sociales latinoamericanos es la territorialidad. En términos generales, tanto para los movimientos urbanos como para los rurales, el territorio aparece como un espacio de resistencia y también, progresivamente, como un lugar de resignificación y creación de nuevas relaciones sociales. Argumenta que la apropiación del territorio nunca es solo material sino también simbólica. La importancia que adquirió la territorialidad, asociada primeramente al hábitat y las condiciones de vida, estuvo ligada a la desarticulación entre empleo y urbanización, operada a fines de los años 60 y 70, que dio lugar a la emergencia a los primeros asentamientos urbanos producto de la ocupación ilegal de tierras. Desde fines de los ' 80 , y con el proceso de recuperación democrática que amplió límites y posibilidades, el territorio se fue erigiendo en el lugar privilegiado de disputa a partir de la implementación de las nuevas políticas sociales, de carácter focalizado, diseñadas con vistas al control y la contención de la pobreza. Más recientemente, la disputa por el territorio ha tenido otras inflexiones a partir de las nuevas modalidades que adoptó la lógica del capital en los espacios considerados estratégicos en términos de recursos naturales. En este sentido, Svampa afirma que estamos en una fase caracterizada por la generalización del modelo extractivoexportador, basado en la extracción de recursos naturales no renovables y la expansión de los agronegocios, necesarios para alimentar el nivel de consumo sostenido y el modelo de acumulación vigente. Por ende, la definición de territorio, más que nunca, se convierte en el locus del conflicto. Así, las acciones de los movimientos campesinos e indígenas, como de aquellos socioambientales, orientadas contra el Estado y contra sectores privados (grandes empresas transnacionales), generalmente se inician con reclamos puntuales, aunque en la 
misma dinámica de lucha tienden a ampliar y radicalizar su plataforma representativa y discursiva, incorporando otros temas, tales como el cuestionamiento a un modelo de desarrollo monocultural y destructivo, y la exigencia de desmercantilización de los llamados "bienes comunes". Estos procesos de movilización conducen a una concepción de la territorialidad que se opone radicalmente al discurso ecoeficientista y la visión desarrollista, propia de la narrativa dominante. En consonancia con este planteo, Raúl Zibechi (2003) sostiene que el actual arraigo territorial de los movimientos sociales constituye una respuesta estratégica de los sectores populares a la crisis de la vieja territorialidad de la fábrica y la hacienda. Agrega que la desterritorialización productiva hizo entrar en crisis a sujetos que vieron evaporarse territorialidades (y sus correspondientes identidades) en las que habían ganado poder y sentido en la etapa anterior, por lo que la referencia a la territorialidad resulta una manifestación de un proceso de reacomodamientos y de reconfiguración social.

Por su parte, Denis Merklen (2005), en un profundo análisis sobre las transformaciones del mundo popular en el período 1976-2001 en la Argentina, propone una lectura que, a nuestro juicio, mantiene vigencia y capacidad explicativa sobre el anclaje territorial de los sectores populares en la actualidad. Merklen sostiene que la desalarización y el retiro masivo del Estado social que caracterizaron el período 1976-2001 modificaron profundamente diversos elementos constitutivos del mundo popular y desestructuraron sus mundos de pertenencia. Ante ello, diversas respuestas fueron desplegadas por los sectores populares, incluyendo el "refugio en el territorio" y el desarrollo de nuevas formas de acción colectiva (cortes de ruta, ocupaciones ilegales de tierras, revueltas y saqueos a comercios) que innovaron las formas clásicas (huelgas, paros, movilizaciones) y constituyeron así un nuevo "repertorio de acción colectiva". ${ }^{2}$ El uruguayo considera que estas acciones encuentran su unidad en los elementos y atributos comunes de una nueva politicidad de los sectores populares cuya emergencia atribuye a las transformaciones operadas: retroceso del Estado y de la integración social vía relación salarial. Destaca, como elemento común de este nuevo contexto, la centralidad que fueron ganando las políticas sociales y la puja por la asistencia social en la agenda política de las clases populares. En un primer momento, las demandas se dirigían a la restauración de las conquistas sociales perdidas o bajo amenaza. En un segundo momento, una vez que la situación se estabilizó en forma de una nueva cuestión social alrededor del empobrecimiento y de la precarización de las relaciones laborales, las luchas populares se dirigieron a la adquisición de prestaciones sociales ligadas a la asistencia (planes sociales varios, subsidios). Merklen, refiriéndose a la Argentina aunque, por nuestra parte, consideramos útil pensarlo también para otros países en Latinoamérica, considera que esta trama social compleja no puede estructurarse más que a nivel local y configura lo que llama la "inscripción territorial" de las clases populares. Sostiene que, en función de los elementos desarrollados, desde comienzos de los años 80 , y en especial a partir de los ' 90 , se vienen desarrollando episodios de cooperación, movilización y protestas colectivas que encuentran su centro

2) Propuesto inicialmente por Charles Tilly, el repertorio de acción colectiva hace referencia a la "totalidad de medios de que disponer un grupo para perseguir intereses compartidos" (Tilly, 1995 citado en Tarrow, 2009, p. 49). El repertorio (huelgas, movilizaciones, cortes de ruta, ocupaciones de espacios públicos, etc.) es, a la vez, un concepto estructural y un concepto cultural que incluye no solo lo que los contendientes hacen cuando están inmersos en un conflicto contra otros, sino lo que saben hacer y lo que los otros esperan que hagan (Tarrow, 2009, p. 59). 
organizativo en el barrio. Esta figura de lo local y territorial se convirtió progresivamente en el principal componente de la inscripción social de una masa creciente de individuos y de familias que no pueden definir su estatus social ni organizar la reproducción de su vida cotidiana exclusivamente a partir de los frutos del trabajo. El proceso de "desafiliación"3 que alcanzó a gran parte de las clases populares encuentra un sustituto de reafiliación en la inscripción territorial. El autor sostendrá que la nueva politicidad de los sectores populares pondrá en el centro de la acción política la disputa por la asistencia social y, para ello, ya no serán las organizaciones tradicionales (partidos políticos, sindicatos) los mejores interlocutores de esta nueva relación. En este escenario, encontramos otro elemento común de esta nueva forma de hacer política de las clases populares: la centralidad de las organizaciones de base territorial.

Como podemos observar, las distintas miradas analizadas coinciden en destacar la relevancia de la dimensión territorial en la constitución, dinámica y procesos de identidad de los actores, organizaciones y movimientos sociales en Latinoamérica. Esta centralidad de las organizaciones de base territorial tiene, o al menos debería tener, un profundo impacto en la forma en que pensamos y trabajamos en el territorio. Territorio que será objeto de múltiples territorializaciones (posibilitadas por la apropiación que hacen las organizaciones vecinales, deportivas, gubernamentales, los jóvenes, las actividades ilegales, etc.), incluyendo la que hacemos las y los universitarios en el marco del proyecto de extensión allí desarrollado.

\section{Repolitizar los territorios y la extensión}

Mariana Arzeno (2018) sostiene que el territorio de intervención de la práctica extensionista es, en muchos casos y al mismo tiempo, el territorio apropiado de las organizaciones sociales con las que la universidad interactúa, por lo que hay que tener en cuenta las ideas, representaciones, objetivos, vivencias y disputas de esos actores. El diálogo de saberes supone concebirnos también nosotros y nosotras (universitarios) como actores que portamos, transitamos y experimentamos múltiples territorialidades que se hacen presentes al momento de pensar la universidad, la sociedad y el espacio que buscamos construir. En este sentido, en las relaciones de poder del territorio y en las múltiples territorializaciones del mismo no están ausentes las que provoca la propia universidad sobre el territorio que interviene en una práctica de extensión. Lo hace al priorizar unos temas sobre otros, al trabajar con algunos actores en desmedro de otros, al portar, siempre, una memoria (en términos de legitimidad o prejuicio negativo) surcada por las anteriores experiencias universitarias en dicho territorio (positivas o negativas).

Asimismo, coincidimos con Bentolila, Kessler y Heinrich (2011) en que el abordaje de lo social se realiza atendiendo al mapa de relaciones de poder preexistente, como también al intrincado conjunto de estrategias desplegadas por una multiplicidad de actores con el objeto de mejorar sus condiciones de vida. En este punto, es oportuno mencionar que el enfoque

3) Merklen señala que retoma el concepto desarrollado por Robert Castel: como descomposición de un sistema de integración social (desde el punto de vista societal) y como pérdida de las inscripciones colectivas (desde el punto de vista de los trabajadores o de los individuos). 
de la corriente de Extensión Crítica Latinoamericana y Caribeña tiene, entre sus principales postulados, los de favorecer procesos políticos y sociales anticapitalistas, antipatriarcales y decoloniales, con el claro propósito político de contribuir al fortalecimiento de los sectores dominados como sujetos históricos protagonistas del cambio social. Si asumimos estos postulados, no solo en lo declarativo sino incrustado en nuestras prácticas, no podemos ser indiferentes acerca de qué tipo de relaciones de poder preexistentes en los territorios (universitario y extrauniversitario) influyen y alimentan nuestras actividades de extensión. Por ello es imprescindible tener una lectura, lo más cercana posible, de los territorios donde transitarán las actividades de extensión con relación a las políticas gubernamentales presentes, actores (institucionales, gubernamentales, de la sociedad civil), intereses, conflictos. Diversas técnicas participativas (a realizar en conjunto con los actores, organizaciones y movimientos sociales) pueden resultar productivas para estos objetivos: mapeo de actores, reconstrucción colectiva de la historia, mapeo y árbol de problemas.

Desconocer los alineamientos, relaciones sociales (y las dinámicas de poder que ellas implican), políticas y conflictos que envuelven todo territorio supone una visión uniforme e ingenua del mismo que, generalmente, favorece y refuerza los procesos de dominación ya presentes y debilita el potencial transformador de la intervención extensionista. Cuando nos preguntamos acerca de qué tipo de relaciones sociales están presentes en el territorio nos referimos a las relaciones propiamente dichas así como a los supuestos éticos e ideológicos que involucran, el modo de vivir y de relacionarse con el otro $u$ otra, el modelo de sociedad que anticipan (individualismo, solidaridad, construcción colectiva, dinámicas patriarcales, colonialidad), en tanto el territorio constituye un lugar de resignificación y creación de nuevas relaciones sociales. En función de esto es que consideramos relevante quitar opacidad al significado de conceptos claves como territorio y poder, explicitándolos y reflexionando sobre sus especificidades no solo en la formulación del proyecto de intervención sino en el desarrollo de la práctica extensionista, ya que siempre nuestra experiencia estará inserta, e interactuará, con las tramas de relaciones sociales allí presentes.

Por otra parte, es preciso considerar que todos los actores y todas las actoras de un proyecto de extensión, universitarios y extrauniversitarios, explícita o implícitamente, tenemos objetivos políticos en nuestra intervención en un determinado territorio. Por ello, resulta clave que la lectura crítica acerca del territorio la dirijamos también hacia la propia universidad, al equipo y al proyecto de extensión, aun en la etapa de formulación. Ello en el sentido de interrogarnos acerca de qué modelo de universidad, qué actores y estructuras de poder dentro del territorio, esta vez propio, universitario, el proyecto de extensión refuerza o problematiza.

\section{Palabras finales}

En este trabajo hemos procurado problematizar algunos de los conceptos que, aun cargados de distintos y contradictorios significados, todos y todas utilizamos frecuentemente en la práctica extensionista. A este respecto, asumimos el planteo de Haesbaert (2011), quien, refiriéndose a categorías como la de territorio, propone denominarlas "categorías de la práctica", dando cuenta de su cotidiana utilización y, sobre todo, constante resignificación. Para efectuar esta operación reflexiva partimos de observar las contribuciones de una potente tradición teórica y experiencial Latinoamericana referida al territorio y sus implicancias. 
Diversos autores de diferentes países, disciplinas y alineamientos teórico-epistemológicos, confluyen en señalar que la dimensión y perspectiva territorial es una de las características más relevantes y originales de los actores, organizaciones y movimientos sociales latinoamericanos. En este sentido, en la tarea de reflexionar sobre los territorios que se convierten en territorio de la extensión esos insumos son un anclaje fundamental.

Por otra parte, hemos intentado fundamentar por qué el territorio constituye una construcción social y cultural que expresa relaciones de poder, siempre conflictivas, alejándonos de concepciones simplificadoras que lo entienden como un espacio homogéneo donde sus integrantes, en función de compartir espacialidad, persiguen fines comunes. Junto con Mançano Fernandes (2017), sostenemos que la conflictividad de las clases y relaciones sociales están presentes en el territorio disputando la definición del orden y control que los distintos sectores sociales tienen sobre él. En esta línea, nos detuvimos, por su pertinencia, en el concepto relacional del poder de Michel Foucault, cuyas hipótesis sobre el funcionamiento del poder y las posibilidades de resistencia son especialmente relevantes en la perspectiva territorial de los movimientos sociales latinoamericanos. Sus observaciones en cuanto a la inmanencia de las relaciones de poder en toda relación social, de gran pertinencia para auscultar nuestra práctica extensionista, nos sirvieron para entender al territorio como un espacio social y culturalmente producido, atravesado por relaciones de poder que, de manera directa o indirecta, consciente o inconsciente, reforzamos o debilitamos con nuestra intervención.

Del examen de estas conceptualizaciones surgió la necesidad de visualizar una dificultad adicional y que es muy frecuente en la práctica extensionista: la categoría de territorio es usualmente utilizada para designar a un otro situado fuera de la universidad y rara vez es una herramienta para pensar y problematizar a la propia universidad como territorio. Territorio atravesado y construido por conflictos, alineamientos y territorializaciones diversas producto de la interacción de los claustros y distintos intereses del campo universitario. Nos preguntamos: ¿acaso es la universidad un espacio libre de relaciones sociales complejas, contradictorias, donde no impactan las dinámicas de poder internas y externas? ¿Acaso no está atravesada por múltiples y divergentes intereses, alineamientos, fines y cosmovisiones? ¿Cuánto de este territorio se entremezcla en nuestras visiones sobre el territorio de las organizaciones y movimientos sociales con las que interactuamos?

Para mejorar nuestra práctica, nos parece clave visibilizar y poner en escena los conflictos y relaciones asimétricas presentes en los territorios donde estamos involucrados (universitario y extrauniversitario) y que con nuestras acciones debilitamos o reforzamos. Referido a esto, también resulta elemental tener claro que son los actores, organizaciones y movimientos sociales quienes tienen la llave acerca de la historicidad del proceso territorial, la singularidad de los actores y los caminos y tiempos posibles de modificación de las condiciones existentes. A esta operación de contraste reflexivo entre los distintos territorios superpuestos que enfrenta la práctica extensionista nos referimos cuando hablamos de repolitizar los territorios. Por un lado, en el sentido de asumir las complejas y conflictivas dinámicas sociales presentes en estos; por el otro, en una suerte de espiral dialéctica, repolitizar la extensión en tanto explicitar las relaciones de poder y conflicto con las que inevitablemente interactuaremos. Por eso proponemos repolitizar los territorios y la extensión y no meramente politizar, ya que son ámbitos que per se, estemos o no conscientes de ello, están ya politizados. 
De esta forma, repolitizándolos, reduciremos los riesgos de pensar y transitar los territorios (universitario y extrauniversitario) como espacios uniformes y homogéneos que, como una suerte de soportes externos, alojan actores sin agencia y despolitizan las relaciones sociales allí presentes. En función de esto resulta necesario poner en palabras, visibilizar y reflexionar, en nuestro trabajo cotidiano y al momento de pensar los distintos proyectos, los múltiples conflictos y relaciones que conviven y disputan. Junto con ello, asumirnos como actores políticos que con nuestra intervención (dentro y fuera de la universidad) impulsamos un determinado modelo de universidad y sociedad. $Y$ a tal efecto siempre interrogarnos acerca de qué actores y estructuras de poder refuerza o problematiza el proyecto de extensión.

Ello nos permitirá mejorar nuestras herramientas para reflexionar sobre nuestras prácticas y avanzar en los procesos de democratización del conocimiento, aportando a la construcción de una sociedad más justa y a una universidad pública incluyente involucrada en la resolución de problemas sociales relevantes. Educación entendida como bien público, gratuita, derecho humano universal y obligación del Estado.

\section{Referencias bibliográficas}

Altschuler, B. (2013). Territorio y desarrollo: aportes de la geografía y otras disciplinas para repensarlos. Theomai, (27-28), 64-79. https://www.redalyc.org/articulo.oa?id=124/12429901005

Arzeno, M., (2018). Extensión en el territorio y territorio en la extensión. Aportes a la discusión desde el campo de la Geografía. +E: Revista de Extensión Universitaria, 8(8), 3-11. https://doi.org/10.14409/extension.v8i8. Ene-Jun.7709

Bentolila, L.; Kessler, M. \& Heinrich, V. (2011). Los laberintos de la extensión. +E: Revista De Extensión Universitaria, 1(1), 46-61. https://doi.org/10.14409/extension.v1i1.446

Castel, R. (1997). Las metamorfosis de la cuestión social. Una crónica del salariado. Paidós.

Castro, E., (2015). Introducción a Foucault. Siglo XXI Editores.

Deleuze, G. (1987). Foucault. Paidós.

Foucault, M. (1990). Historia de la Sexualidad 1. La voluntad de saber. Siglo XXI Editores.

Haesbaert, R. (2013). Del mito de la desterritorialización a la multiterritorialidad. Cultura y representaciones sociales, 8(15) 8-42. http://www.scielo.org.mx/pdf/crs/v8n15/v8n15a1.pdf

Haesbaert, R. (2011). El mito de la desterritorialización: del "fin de los territorios" a la multiterritorialidad. Siglo XXI Editores.

Lopes de Souza, M. (2001). O território: sobre espaço e poder. Autonomia e Desenvolvimento. En Castro, I. E. de; Gomes, P. C. da C.; Corrêa, R. L. (Orgs.), Geografia: conceitos e temas. Bertrand.

Manzanal, M. (2014). Desarrollo: Una perspectiva crítica desde el análisis del poder y del territorio. Instituto Argentino para el Desarrollo Económico; Realidad Económica, 5(283), 17-48 http://hdl.handle.net/11336/35139 Mançano Fernandes, B. (2005). Movimientos socioterritoriales y movimientos socioespaciales. Revista OSAL, Observatorio Social de América Latina, (16). CLACSO. https://web.ua.es/en/giecryal/documentos/documentos839/docs/bmfunesp-5.pdf

(2017). Territorios y Soberanía Alimentaria. Revista latinoamericana de estudios rurales ii, (3), pp $22-39$. http://www.ceil-conicet.gov.ar/ojs/index.php/revistaalasru/article/view/114/111

Merklen, D. (2005). Pobres ciudadanos. Las clases populares en la era democrática (Argentina, 1983-2003). Gorla. Sack, R. (1986). La territorialidad humana: su teoría e historia. Universidad de Cambridge. 
Svampa, M. (2017). Movimientos Sociales, tradiciones políticas y dimensiones de la acción en América Latina". Del cambio de época al fin del ciclo. Gobiernos progresistas, extractivismo y movimientos sociales en América Latina (pp. 27-52). Edhasa.

Tarrow, S. (2009). El poder en movimiento. Los Movimientos sociales, la acción colectiva y la política. Alianza Editorial.

Tommasino, H. y Rodríguez, N. (2011). Tres tesis básicas sobre extensión y prácticas integrales en la Universidad de la República. En Integralidad: tensiones y perspectivas. Extensión Universitaria.

Zibechi, R. (2003). Los movimientos sociales latinoamericanos: tendencias y desafíos. OSAL: Observatorio Social de América Latina, (9). CLACSO. 